\title{
Traditional textile motifs and designs of Mishing community of Assam
}

Lizamoni Chungkrang and Ava Rani Phukan

Received: 03.11.2017; Revised: 04.04.2018; Accepted: 22.04.2018

See end of the paper for authors' affiliations

Lizamoni Chungkrang Department of Textiles and Apparel Designing, Faculty of Home Science, Assam Agricultural University, Jorhat (Assam) India Email : kutumlucy@gmail.com
ABSTRACT : India is a nation with vast and ancient traditions. The country blossoms with colourful traditional dresses that various communities and tribes of different states wear. The present study was an attempt to study the traditional textile motifs and designs of Mishing community. The study aimed to document the colour combinations, form of designs, different techniques used to form the designs and the traditional names of the motifs and designs. Data were gathered through personal visit to the common weavers and photographs were taken to support the study. This type of study will not only help in the preservation of the traditional motifs and designs but also broaden the design base for the textiles products.

KEY WORDS: Traditional textiles, Traditional motifs and designs, Mishing community

- HOW TO CITE THIS PAPER : Chungkrang, Lizamoni and Phukan, Ava Rani (2018). Traditional textile motifs and designs of Mishing community of Assam. Asian J. Home Sci., 13 (1) : 195-201, DOI: 10.15740/ HAS/AJHS/13.1/195-201. Copyright@ 2018: Hind Agri-Horticultural Society. 